\title{
ANATOMIA DA MADEIRA DE Xylosma tweedianum (Clos) Eichler (Flacourtiaceae)
}

José Newton Cardoso Marchiori e Fernanda Pozzera

Departamento de Ciências Florestais - CCR

UFSM - Santa Maria, RS

\section{RESUMO}

O presente trabalho descreve a estrutura anatômica da madeira de Xylosma tweedianum (Clos) Eichl. São fornecidos dados quantitativos e histométricos do xilema secundário, além de ilustrações do tecido lenhoso. As principais caracteristicas observadas correspondem ao descrito na literatura para a família Flacourtiaceae e gênero Xylosma. Destacam-se as placas de perfuração simples, a ausência de parênquima axial, os raios marcadamente heterogêneos, as fibras libriformes e a presença de elementos vasculares muito longos, com espessamentos espiralados.

Palavras Chave: Anatomia da Madeira, Flacourtiaceae, Xylosma, Xylosma tweedianum.

\section{SUMMARY}

MARCHIORI, J.N.C., POZZERA, F. Wood Anatomy of Xylosma tweedianum (Clos) Eichl. (Flacourtiaceae).

This study describes the wood anatomy of Xylosma tweedianum (Clos) Eichl. Aside from quantitative and histometric data, 
photomicrographs of the anatomical structure are furnished. The most important features observed in the wood are the same described in the literature to the Flacourtiaceae and genus Xylosma. Among these features are the absence of wood parenchyma and the presence of only simple perforation plates in vessels, of heterogeneus type-I rays, of libriform fibers and of spiral thickenings on the walls of very long vessel members.

Keywords: Wood Anatomy, Flacourtiaceae, Xylosma, Xylosma tweedianum.

\section{INTRODUÇÃO}

A família Flacourtiaceae apresenta diversos gêneros $e$ numerosas espécies de árvores pequenas na flora sul-brasileira, que participam dos estratos florestais inferiores e fornecem madeiras ainda desconhecidas sob o ponto de vista anatômico.

Com cerca de 95 espécies de árvores ou arbustos, o gênero Xylosma G. Forster distribui-se da América Central à América do Sul, ocorrendo ainda no sudeste asiático e em numerosas ilhas do oceano Pacífico. Reúne espécies predominantemente dióicas, que se distinguem pela presença de espinhos simples ou ramificados, tanto no tronco como nos ramos. As folhas, alternas, pecioladas e desprovidas de estípulas, são geralmente glandular-crenadas ou serreadas, persistentes ou raramente deciduais (KLEIN \& SLEUMER, 1984). A casca contém tanino, os frutos muitas vezes produzem corantes e as madeiras, moderadamente pesadas, duras e de textura fina, são como regra pouco usadas, exceto como lenha (RECORD \& HESS, 1949).

Xylosma tweedianum é uma espécie de árvores pequenas (até $7 \mathrm{~m}$ ), de copa globosa, densamente ramificada e com folhagem caducifólia. Apresenta casca externa muito fissurada e ramos avermelhados, providos de lenticelas acinzentadas e espinhos simples, de até $5 \mathrm{~cm}$ (LOMBARDO, 1964). As folhas, alternas, simples e ovaladas ou romboédrico-elípticas, medem de 4 a $6 \mathrm{~cm}$ de comprimento por 2 a $3 \mathrm{~cm}$ de largura (MUÑOZ et al., 
1993). Apresentam pecíolo de 5 a $8 \mathrm{~cm}$, ápice desde obtuso até acuminado, base cuneada e margem crenado-serreada, provida de glândulas (SLEUMER, 1953). As flores, produzidas ao final do inverno ou início da primavera, são unissexuais e agrupadas em fascículos axilares, à semelhança das demais espécies do gênero. Os frutos são bagas ovóides, de cor preta e com cerca de $5 \mathrm{~mm}$ de comprimento (DIMITRI, 1980). Sua área de distribuição geográfica compreende o sudeste brasileiro, o Uruguai e as províncias argentinas de Corrientes e Entre Rios (KLEIN \& SLEUMER, 1984), habitando principalmente as florestas de galeria da região campestre. Conhecida pelos nomes de sucará ou espinho-de-judeu, distingue-se por sua grande plasticidade morfológica, motivo pelo qual dispõe de uma riquíssima sinonímia botânica, salientando-se os binômios Xylosma warburgii (Briq.) Briq., Xylosma sleumeri Herter e Xylosma venosum N.E. Brown var. populneum Sleumer ex Lombardo.

A anatomia da madeira das Flacurtiáceas distingue-se pela presença de vasos geralmente pequenos, solitários ou em múltiplos radiais, com placas de perfuração simples, menos comumente escalariformes, de parênquima axial ausente ou muito escasso, de raios marcadamente heterogêneos e de fibras septadas, com pontoações simples ou distintamente areoladas (METCALFE \& CHALK, 1972).

Poucas Flacurtiáceas nativas no sul do Brasil foram estudadas quanto aos aspectos anatômicos da madeira, salientando-se as descrições de Casearia rupestris Eichl. (MARCHIORI \& GOMES, 1980) e de Prockia crucis L. (GOMES \& MARCHIORI, 1981).

Para o gênero Xylosma, MILLER (1975) relaciona a presença de poros muito pequenos a médios, moderadamente numerosos a muito numerosos (17 - 103 poros $/ \mathrm{mm}^{2}$ ) e geralmente distribuídos em múltiplos radiais de 2 a 3 . São referidos elementos vasculares médios a moderadamente longos (633 - 851 - $1143 \mu \mathrm{m}$ ), com placas de perfuração exclusivamente simples, delgados espessamentos espiralados na parede e pontoações intervasculares alternas, pequenas a médias $(4-8 \mu \mathrm{m})$, de forma circular ou poligonal. As fibras, septadas e com pontoações simples ou 
areoladas, variam de 1128 a $1802 \mu \mathrm{m}$ de comprimento e os raios multisseriados, com 2 a 5 células de largura, apresentam abundantes cristais primáticos em células eretas (MILLER, 1975).

O presente estudo sobre a estrutura do xilema secundário de Xylosma tweedianum (Clos) Eichl. visa trazer novos esclarecimentos sobre a anatomia das Flacourtiaceae e um maior conhecimento sobre as madeiras sul-riograndenses desta família.

\section{MATERIAIS E MÉTODOS}

O material estudado é procedente do Rio Grande do Sul e consiste de uma amostra de madeira, com o respectivo material botânico, conservada no Herbário do Departamento de Ciências Florestais (HDCF), com os seguintes registros:

- Marchiori, J.N.C., no 418 (01/8/1986). Floresta ciliar do rio Ibicuí, São Vicente do Sul, RS. (HDCF no 2397).

$\mathrm{Da}$ amostra de madeira foram preparados 3 corpos de prova, orientados para a obtenção de cortes anatômicos nos planos transversal, longitudinal radial e longitudinal tangencial.

Os cortes anatômicos foram coloridos com acridina-vermelha, crisoidina e azul-de-astra (DUJARDIN, 1964) e montados em lâminas permanentes, com "Entellan". No preparo de lâminas de macerado usou-se a técnica de Jeffrey (FREUND, 1970), coloração com safranina e o mesmo meio de montagem anteriormente referido.

Para as medições dos elementos celulares constituintes da madeira seguiram-se as recomendações da COPANT (1973). As determinações histométricas relativas aos diferentes tipos celulares e às classes de raios quanto à largura em número de células, foram obtidas pela metodologia recomendada por TEIXEIRA (1977) e MARCHIORI (1980). O conjunto destes dados quantitativos é apresentado na Tabela 1. 
As fotomicrografias que ilustram a descrição anatômica foram realizadas no Laboratório de Anatomia da Madeira, da Universidade Federal do Paraná.

\section{DESCRIÇÃO DA MADEIRA}

Vasos: Porosidade difusa, uniforme (Figura 1.A,B). Poros ocupando $30,3 \%$ da seção transversal da madeira; extremamente numerosos (143-290-510/ $\mathrm{mm}^{2}$ ), muito pequenos (30 - 41,5 - $\left.55 \mu \mathrm{m}\right)$, de seção poligonal (Figura 1.B) e dispostos principalmente em múltiplos radiais e racemiformes, menos comumente solitários (Figura 1.A,B). Elementos vasculares muito longos $(380-795-1130 \mu \mathrm{m})$, com placas de perfuração exclusivamente simples (Figura 2.B), providos de espessamentos espiralados na parede (Figura 2.A,B; 3.B) e com apêndices curtos (20 - 76 $260 \mu \mathrm{m})$, normalmente em ambas as extremidades. Pontoações intervasculares pequenas a médias $(6-8,1-10 \mu \mathrm{m})$, em arranjo alterno, de forma poligonal e com abertura inclusa (Figura 3.B). Pontoações raiovasculares pequenas $(3-4,1-5 \mu \mathrm{m})$ e arredondadas (Figura 2.A).

\section{Parênquima axial: Ausente.}

Raios: Ocupando $12,7 \%$ do volume da madeira. Tecido radial heterogêneo, do tipo I de Kribs. Raios de relacionamento normal, por vezes axialmente fusionados; raios agregados, ausentes. Raios muito numerosos (15 - 18,3 - 22 raios $/ \mathrm{mm}$ ), em sua maioria trisseriados $(49,3 \%)$, menos comumente bisseriados $(23,7 \%)$ e unisseriados $(22,3 \%)$, raramente tetrasseriados $(4,7 \%)$. Raios unisseriados extremamente finos $(6,0-8,2$ $10,0 \mu \mathrm{m})$, de baixos a altos $(210-409-910 \mu \mathrm{m})$, com $3-7-16$ células de altura e compostos de células quadradas e eretas. Os raios multisseriados variam de baixos a altos $(260-508-840 \mu \mathrm{m})$, com $7-13-22$ células de 
altura (Figura 3.A) e são finos ou muito finos $(22,5-32,5-50 \mu \mathrm{m})$, reunindo um curto corpo multisseriado central, de células procumbentes e longas margens unisseriadas, de células quadradas e eretas (Figura 2.A,B). Células cristalíferas, envolventes, esclerosadas, latericuliformes, mucilaginosas, oleíferas e canais intercelulares, ausentes.
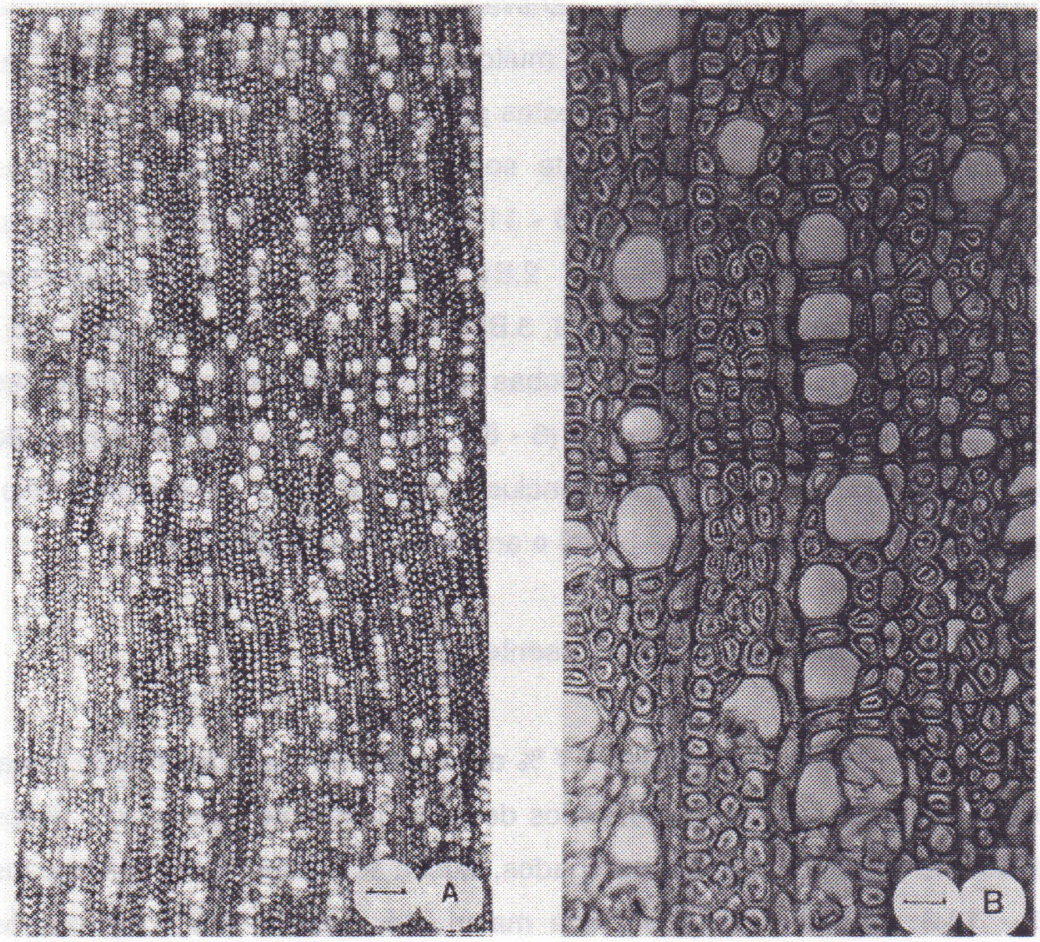

FIGURA 1. Aspectos da madeira em plano transversal. A. Porosidade difusa, poros extremamente numerosos, muito pequenos e arranjados principalmente em múltiplos radiais e racemiformes; $($ Escala $=100 \mu \mathrm{m})$. B. Detalhe de um limite de anel de crescimento, mostrando 2 fileiras de fibras radialmente achatadas no término do anel, poros poligonais e fibras de paredes espessas; (Escala $=25 \mu \mathrm{m})$. 

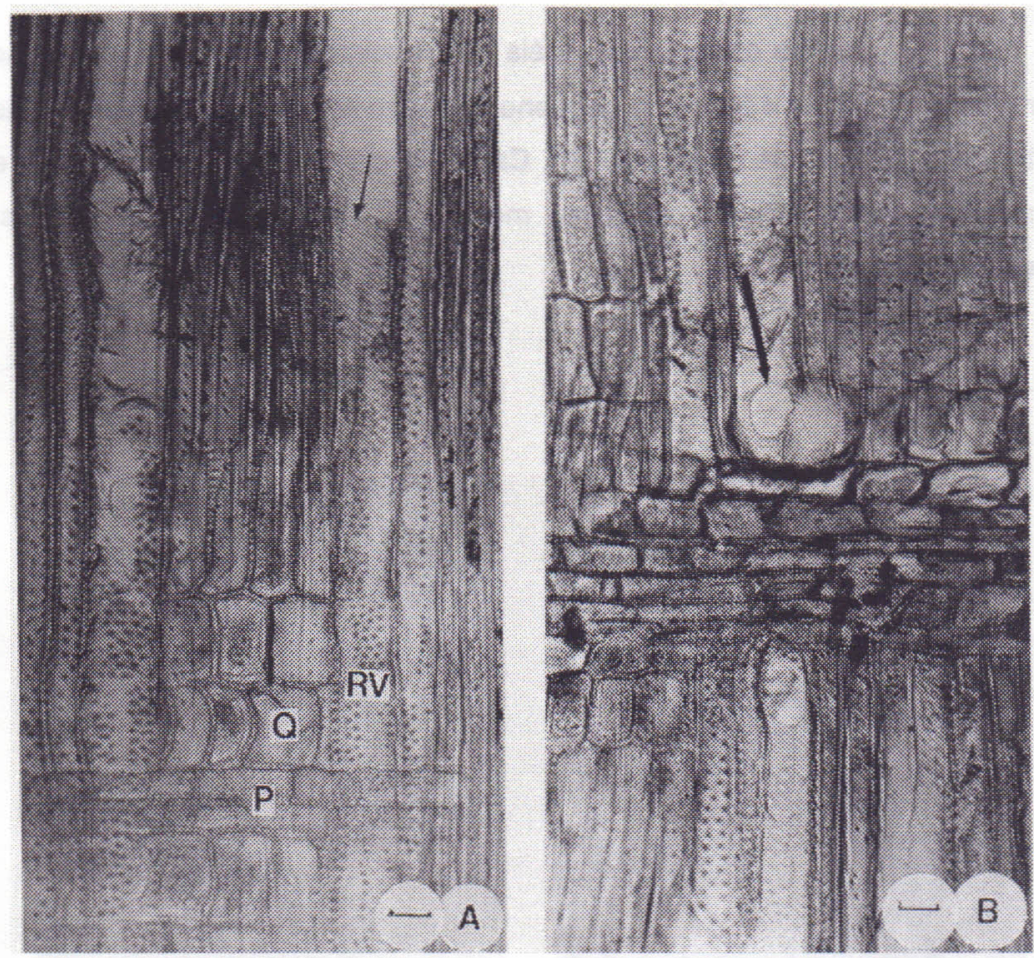

FIGURA 2. Aspectos da madeira em plano longitudinal radial. A. Raio heterogêneo, com células procumbentes $(P)$ e quadradas $(Q)$, vasos com espessamentos espiralados na parede (seta) e pontoações raio-vasculares (RV); (Escala $=25 \mu \mathrm{m})$. B. Raio heterogêneo, vaso com espessamentos espiralados e placas de perfuração simples (seta); (Escala $=25 \mu \mathrm{m})$.

Fibras: Tecido fibroso proeminente, ocupando $57 \%$ do volume da madeira. Fibras libriformes, septadas, freqüentemente gelatinosas e com abundantes pontoações simples em forma de fenda, mais abundantes na face radial da parede celular. São curtas $(620-1157-1620 \mu \mathrm{m})$, estreitas $(13,8-21-30 \mu \mathrm{m})$ e de paredes espessas $(3,8-6.0-8,1 \mu \mathrm{m})$ (Figura 1.B). 
Outros caracteres: Anéis de crescimento distintos, marcados por uma faixa de 2 a 4 fibras de pequeno diâmetro radial e com paredes mais fortemente lignificadas (Figura 1.A,B). Canais secretores, tubos lacticíferos $e$ taniníferos, líber incluso, máculas medulares, estratificação e cristais, ausentes na madeira.
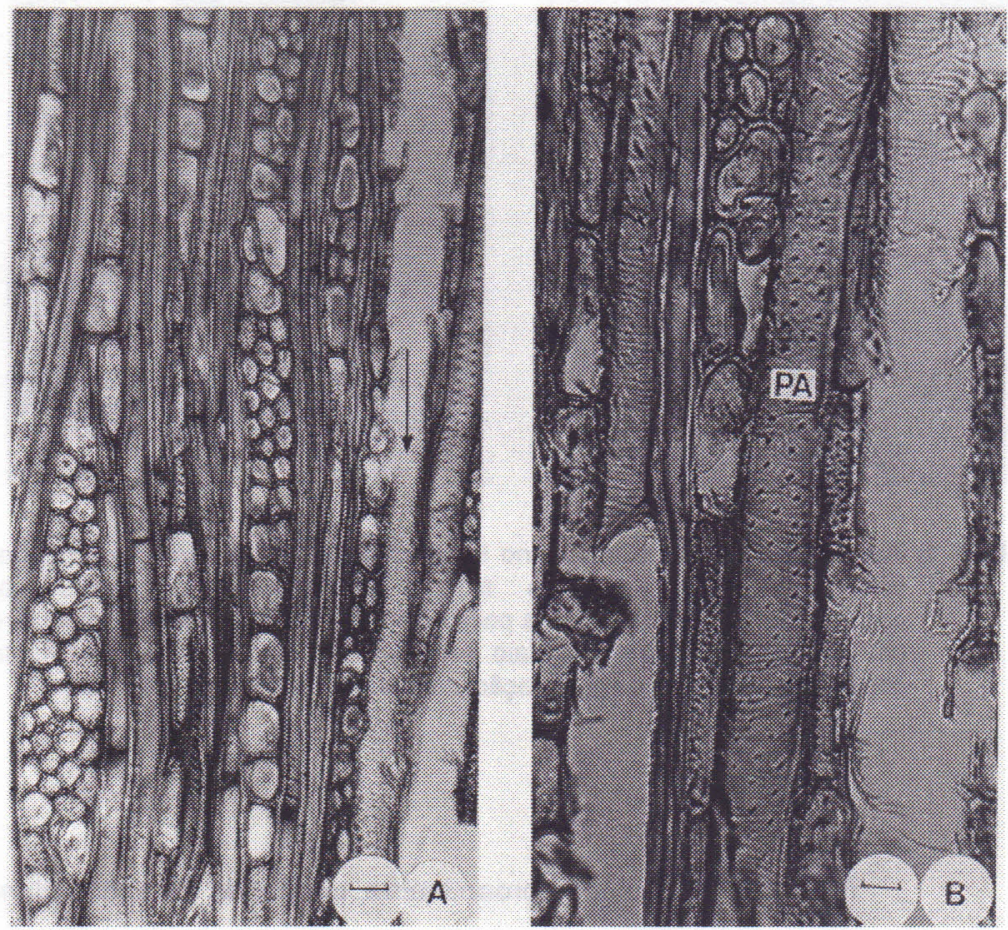

FIGURA 3. Aspectos da madeira em plano longitudinal tangencial. A. Raios multisseriados com 2 a 4 células de largura e elementos vasculares com espessamentos espiralados na parede (seta); (Escala $=25 \mu \mathrm{m})$. B. Detalhe de raio multisseriado, pontuado intervascular alterno (PA) e delgados espessamentos espiralados na parede de vaso (Escala $=12,5$ $\mu \mathrm{m})$. 


\section{ANÁLISE DA ESTRUTURA ANATÔMICA}

Os principais detalhes anatômicos observados na madeira de Xylosma tweedianum (Clos) Eichl., são citados por RECORD \& HESS (1949) e METCALFE \& CHALK (1972), como tendo ampla ocorrência na família Flacourtiaceae: poros muito pequenos, extremamente numerosos e em múltiplos radiais, elementos vasculares com placas de perfuração simples, raios marcadamente heterogêneos, fibras septadas e parênquima axial ausente.

Dos caracteres qualitativos ressaltam-se ainda os delgados espessamentos espiralados dos vasos, o contorno poligonal dos poros em seção transversal e a presença de fibras libriformes com pontoações simples, mais abundantes na face radial da parede. A formação de anéis de crescimento distintos, marcados por uma estreita camada de fibras radialmente achatadas, constitui um aspecto pouco freqüente em espécies brasileiras da família, explicando-se pela caducidade foliar e conseqüente paralisação da atividade cambial, em meados do outono.

A largura dos raios em número de células e os valores de comprimento de elementos vasculares e de fibras, observados em Xylosma tweedianum, correspondem aos intervalos referidos por MILLER (1975), para o gênero em questão. Com relação às pontoações intervasculares, observou-se um diâmetro ligeiramente maior do que o referido, no mesmo trabalho, para as demais espécies de Xylosma. Resta acrescentar que não foram observados cristais nos raios lenhosos de Xylosma tweedianum, ao contrário do referido na literatura, para a maioria das espécies dos gênero.

A ocorrência de raios heterogêneos de Tipo I, com suas longas margens unisseriadas de células quadradas e eretas, é aspecto muito freqüente nas Flacurtiáceas, onde constitui uma estrutura homóloga ao parênquima axial, que atua no armazenamento de substâncias de reserva. A natureza e a elevada freqüência de raios, por sua vez, parece justificar a ausência de parênquima axial na madeira. 
A estrutura anatômica indica uma posição filogenética intermediária para a espécie em estudo, reunindo caracteres primitivos, como elementos vasculares muito longos e raios heterogêneos Tipo I, com a presença exclusiva de placas de perfuração simples e de fibras libriformes, tidos como evoluídos.

\section{CONCLUSÕES}

O estudo anatômico da madeira de Xylosma tweedianum (Clos) Eichl. indica as seguintes conclusões:

- Os principais caracteres observados, correspondem ao descrito na literatura para a família Flacourtiaceae.

- A estrutura anatômica indica uma posição filogenética intermediária, reunindo caracteres evoluídos e primitivos.

- Ocorrem poros extremamente numerosos, muito pequenos, de seção poligonal e em múltiplos principalmente radiais.

- Os elementos vasculares, muito longos e com placas de perfuração simples, apresentam espessamentos espiralados e pontoações intervasculares alternas, de diâmetro médio.

- A madeira apresenta estrutura radial heterogênea Tipo I e raios com até 4 células de largura, compostos de células procumbentes, na parte multisseriada central e por células quadradas eretas, nas longas margens unisseriadas. 


\section{LITERATURA CITADA}

COPANT - COMISSÃO PANAMERICANA DE NORMAS TECNICAS.

Descrição macroscópica, microscópica e geral da madeira - esquema I de recomendação. Colômbia, 1973. 19 p. (COPANT 30).

DIMITRI, M.J. Encliclopedia Argentina de Agricultura y Jardineria. Buenos Aires: Ed. ACME S.A.C.I., 1980.1161 p.

DUJARDIN, E.P. Eine neue holz-zellulosenfaerbung. Mikrokosmos, n. 53, p. 94, 1964.

FREUND, H.H. Handbuch der Mikroskopie in der Technik. Frankfurt: Umscham Verlag, 1970. 375 p.

GOMES, A.V., MARCHIORI, J.N.C. Estudo anatômico da madeira e da casca de Prockia crucis L. (Flacourtiaceae). Ciência e Natura, v.3, n. 3, p. 45$58,1981$.

KLEIN, R.M., SLEUMER, H.O. Flacourtiáceas. In: REITZ, R. Flora llustrada Catarinense. Itajaí, Herbário Barbosa Rodrigues, 1984. 96 p.

LOMBARDO, A. Flora arborea y arborescente del Uruguay. Montevideo: Concejo Departamental, 1964. $151 \mathrm{p}$.

MARCHIORI, J.N.C. Estudo anatômico do xilema secundário e da casca de algumas espécies dos gêneros Acacia e Mimosa, nativas no Estado do Rio Grande do Sul. Curitiba, Universidade Federal do Paraná. Curso de Pós-Graduação em Engenharia Florestal, 1980. 186 f. Dissertação de Mestrado

MARCHIORI, J.N.C., GOMES, A.V. Anatomia da madeira e da casca de Casearia rupestris Eichl. In: Anais do IV Congresso Florestal Estadual. Nova Prata, 1980. p. 225-237.

METCALFE, C.R., CHALK, L. Anatomy of the Dicotyledons. Oxford: Clarendon Press, 1972. 1500 p.

MILLER, R.B. Systematic Anatomy of the Xylem and comments on the relationships of Flacourtiaceae. Journal of the Arnold Arboretum, v. 56, n. 1, p. 20-102, 1975. 
MUÑOZ, J., ROSS, P., CRACCO, P. Flora indígena del Uruguay. Montevideo: Ed. Hemisferio Sur, 1993. 284 p.

RECORD, S.J., HESS, R.W. Timbers of the New World. New Haven: Yale University Press, 1949. 640 p.

SLEUMER, H. Las Flacourtiáceas Argentinas. Lilloa, Tucuman, v. 26, p. 5$56,1953$.

TEIXEIRA, L.L. Identificação botânico-dendrológica e anatômica de seis espécies euxilóforas do sudoeste paranaense. Curitiba, Universidade Federal do Paraná. Curso de Pós-Graduação em Engenharia Florestal, 1977. 112 f. Dissertação de Mestrado. 
TABELA 1. Dados quantitativos da estrutura anatômica da madeira de Xylosma tweedianum.

\begin{tabular}{|c|c|c|c|c|}
\hline CARACTERÍSTICA ANATÔMICA & $\begin{array}{l}\text { MÍNIM } \\
\text { o } \\
\text { VALOR }\end{array}$ & MÉDIA & $\begin{array}{l}\text { VALOR } \\
\text { MÁXIMO }\end{array}$ & $\begin{array}{l}\text { DESVIO } \\
\text { PADRÃO }\end{array}$ \\
\hline 1. Fração de poros (\%) & 27 & 30,3 & 33,0 & 2,13 \\
\hline 2. Freqüência de poros (poros/mm²) & 143 & 290,0 & 510,0 & 70,88 \\
\hline 3. $\varnothing$ poros $(\mu \mathrm{m})$ & 30 & 41,5 & 55,0 & 6,29 \\
\hline 4. Espessura parede de poros $(\mu \mathrm{m})$ & 2,5 & 3,7 & 5,0 & 0,88 \\
\hline 5. C. elementos vasculares $(\mu \mathrm{m})$ & 380,0 & 795,0 & 1130,0 & 134,52 \\
\hline 6. C. de apêndices $(\mu \mathrm{m})$ & 20,0 & 76,0 & 260,0 & 53,19 \\
\hline 7. $\varnothing$ pont. intervasculares $(\mu \mathrm{m})$ & 6,0 & 8,1 & 10,0 & 0,86 \\
\hline 8. $\varnothing$ pont. raio-vasculares $(\mu \mathrm{m})$ & 3,0 & 4,1 & 5,0 & 0,57 \\
\hline 9. Fração de raios (\%) & 10,0 & 12,7 & 17,0 & 2,21 \\
\hline 10. Freqüência de raios (raios $/ \mathrm{mm}$ ) & 15,0 & 18,3 & 22,0 & 16,95 \\
\hline 11. Fração raios unisseriados (\%) & 20,0 & 22,3 & 25,0 & 2,06 \\
\hline 12. H. raios unisseriados $(\mu \mathrm{m})$ & 210,0 & 409,0 & 910,0 & 140,08 \\
\hline 13. H. raios unisseriados (células) & 3. & 7 & 16 & 2,98 \\
\hline 14. L. raios unisseriados $(\mu \mathrm{m})$ & 6,0 & 8,2 & 10,0 & 3,36 \\
\hline 15. Fração raios bisseriados (\%) & 16,0 & 23,7 & 27,0 & 3,98 \\
\hline 16. Fração raios trisseriados (\%) & 48,0 & 49,3 & 50,0 & 0,81 \\
\hline 17. Fração raios tetrasseriados (\%) & 3,0 & 4,7 & 10,0 & 2,87 \\
\hline 18. $\mathrm{H}$. raios multisseriados $(\mu \mathrm{m})$ & 260,0 & 508,0 & 840,0 & 158,47 \\
\hline 19. H. raios multisseriados (células) & 7 & 13 & 22 & 3,77 \\
\hline 20. L. raios multisseriados $(\mu \mathrm{m})$ & 22,5 & 32,5 & 50,0 & 6,61 \\
\hline 21. L. raios multisseriados (células) & 2 & 2,6 & 4 & 0,53 \\
\hline 22. Fração de fibras (\%) & 51,0 & 57,0 & 61,0 & 3,55 \\
\hline 23. Comprimento de fibras $(\mu \mathrm{m})$ & 620,0 & 1157,0 & 1620,0 & 180,94 \\
\hline 24. Diâmetro de fibras $(\mu \mathrm{m})$ & 13,8 & 21,0 & 30,0 & 3,81 \\
\hline 25. Diâmetro lumem de fibras $(\mu \mathrm{m})$ & 3,8 & 9,0 & 17,5 & 3,37 \\
\hline 26. Espessura parede de fibras $(\mu \mathrm{m})$ & 3,8 & 6,0 & 8,1 & 1,25 \\
\hline
\end{tabular}


172 Rev. Ciência e Natura, Santa Maria, 19: 159 - 171, 1997 